\title{
Rio Grande do Norte
}

National Cancer Institute

\section{Source}

National Cancer Institute. Rio Grande do Norte. NCI Thesaurus. Code C156332.

A state in the Northeast Region of Brazil. Its capital is Natal. 